\title{
TEORIA CRÍTICA E OS (DES)CAMINHOS DA TECNOCIÊNCIA: REFLEXÕES MARCUSEANAS
}

\author{
Maria de Fátima Vieira Severiano ${ }^{1}$ \\ Pablo Severiano Benevides2 \\ Valdemir Pereira de Queiroz Neto ${ }^{3}$
}

\begin{abstract}
Resumo:
O presente artigo tem por objetivo discutir a problemática do progresso técnico favorecido pelas produções científicas a partir do referencial teórico da Escola de Frankfurt, especialmente as contribuições de Herbert Marcuse. Para tal propósito, os conceitos de Teoria Crítica, Progresso Técnico, Progresso Humanitário e Racionalidade Instrumental são discutidos, problematizando a relação entre ciência e a racionalidade privilegiada pelo mercado com relevantes impactos nas produções da ciência contemporânea. Metodologicamente, trata-se de uma pesquisa teórica, de natureza qualitativa e de inspiração crítica, em que nos valemos da proposta da teoria crítica, cuja abordagem micrológica concebe o particular como um valioso índice que remete ao todo. Em seu desenvolvimento, discutimos as atuais formas de produção científica, a partir das relações entre razão instrumental e tecnologia, explorando as noções de técnica e tecnologia e atualizando essa discussão com as questões relacionadas à onipresença dos aparatos tecnológicos. Concluímos que há significativo direcionamento das produções alinhadas à racionalidade instrumental que determina a eficiência, produtividade e lucratividade como valores centrais para a manutenção do sistema capitalista e impede o desenvolvimento de contribuições para a melhoria da sociedade, mantendo a injustiça e a desigualdade social.
\end{abstract}

Palavras-chave: Teoria Crítica. Progresso. Produções Científicas. Tecnologia.

\section{CRITICAL THEORY AND THE (DE)TOURS OF SCIENCE: MARCUSEAN REFLECTIONS}

\begin{abstract}
:
The present article has the objective of discussing the matter of technical progress favored by the scientific productions from the theoretical perspective of the Frankfurt School, specially the contributions of Herbert Marcuse. To achieve such purpose, the concepts of Critical Theory, Technical Progress, Humanitarian

1 Professora titular da Universidade Federal do Ceará no Departamento de Psicologia e Programa de PósGraduação, com pesquisas na área de Psicologia Social relacionadas à Teoria Crítica, Cultura do consumo, Novas Tecnologias e Temporalidades Contemporâneas. É psicóloga, graduada pela Universidade Federal do Ceará (1982), com Doutorado em Ciências Sociais Aplicadas à Educação pela Universidade Estadual de Campinas - UNICAMP (1999) e com doutorado sanduíche no Depto. de Psicologia Social da Facultad de Ciencias Politicas y Sociologia da Universidad Complutense de Madrid. E-mail: fatimaseveriano@gmail.com.

2 Professor Permanente do Programa de Pós-Graduação em Psicologia da UFC - Fortaleza e Professor Adjunto III do Curso de Psicologia da UFC - Sobral. Pós-doutor em Filosofia da Educação pela Universitat de Barcelona (2016), Doutor em Educação pela Universidade Federal do Ceará (2013), Mestre em Filosofia (2008) e Graduado em Psicologia pela mesma instituição. Dedica-se aos temas relacionados ao neoliberalismo, às formas contemporâneas de exercício do poder, da dominação e das resistências, à biopolítica, aos estudos foucaultianos e às relações entre Psicologia Social e as teorias críticas e pós-críticas contemporâneas. E-mail: pabloseverianobenevides@ hotmail.com.

3 Professor Adjunto da Universidade Federal do Ceará - Campus Quixadá, possui graduação em Psicologia (UFC), mestrado em Psicologia na linha de pesquisa de Cultura e Subjetividade Contemporânea pela UFC e Doutorado em Psicologia (UFC), desenvolvendo estudos com ênfase em Psicologia Social, atuando principalmente nos seguintes temas: cultura contemporânea, sociedade de consumo, tempo livre, esportividade, cultura do narcisismo, indústria cultural e novas tecnologias. E-mail: valdemirpsiqueiroz@gmail.com.
\end{abstract}


Progress and Instrumental Rationality are discussed, addressing the problem of the relation between science and the rationality privileged by the market with relevant impact on contemporaneous scientific productions. Methodologically, it is an theoretical research of qualitative nature and critical inspiration, in which we are guided by the Critical Theory proposal, whose micrological approach conceives the particular as a valuable index addressed to the whole scenario. In its development, firstly, current forms of scientific productions are discussed and from the relations among instrumental rationality, technology e and a machinated human, we explore concepts of technique and technology and its onipresence. It has been concluded that there is a significant furtherance of productions aligned to the instrumental rationality which determines efficiency, productivity and profitability as essential values to the maintenance of the capitalist system and it impedes the development of contributions to the improvement of society, resulting in social inequality and injustice.

Keywords: Critical Theory, Progress, Scientific Productions. Technology.

\section{Introdução}

O presente artigo busca refletir acerca da onipresente mediação da tecnologia na sociedade contemporânea em suas determinações histórico-sociais, de modo a questionar certa noção de "progresso" a ela vinculada, bem como suas implicações para a emancipação humana. Para tal, serão discutidos alguns conceitos, tais como o de técnica, o de racionalidade instrumental e os conceitos de progresso tecnológico e progresso humanitário - situando, portanto, o trabalho no horizonte da Teoria Crítica; e, em especial, em uma filiação mais específica ao pensamento de Herbert Marcuse.

As transformações técnicas, sociais e econômicas que permearam o movimento filosófico do Iluminismo estabeleceram ideais com base nos quais a humanidade passou a ser orientada - ideais estes que estavam em franca em oposição à sociedade antecessora, predominantemente regida pelos mitos e dogmas. Assim, o conhecimento científico, apoiado fundamentalmente pela metodologia do positivismo e pelos avanços técnicos emergentes à época, propiciou ao homem um maior controle sobre as forças da natureza. Surge, então, um novo discurso de desencantamento do mundo cujo subsolo fundamental é a racionalidade tecnocientífica. Os benefícios trazidos em nome da ciência expandiram o horizonte espaçotemporal do homem. O conhecimento desenvolveu-se, apoderou-se da natureza e ultrapassou os limites de seu ideário com pretensões emancipatórias, dando por tantas vezes vazão à destruição racionalmente planejada e justificada. A Primeira Grande Guerra expôs um embate entre os mais avançados e desenvolvidos países. Expôs também a necessidade de reflexão sobre os fins da ciência e um questionamento em face ao entusiasmo para com as frentes em que o conhecimento poderia se desenvolver e se especializar, em nome do progresso. Segundo alerta Soares (2002), “[...] temos construído várias estratégias de ação individuais e/ou coletivas que podem nos conduzir na direção oposta dos nossos verdadeiros interesses ou, simplesmente, nos levar a uma marcha insensata e autodestrutiva" (p. 38).

\begin{tabular}{|c|c|c|c|c|}
\hline Govista Dialectus & Ano 8 & n. 14 & Janeiro - Julho 2019 & p. 121-146 \\
\hline
\end{tabular}


Assim, assumimos a reflexão frankfurtiana segundo a qual a racionalidade em que se apoia o progresso técnico, apesar de alegar a promoção de certos benefícios para a humanidade, ao não incluir uma reflexão ética sobre os seus fins, mistifica-se em vista de seu distanciamento da realidade da vida humana. A ciência, hoje, mantém o homem em um estado de submissão às "verdades" constituídas em modelos científicos "inquestionáveis" à semelhança dos antigos mitos que ela mesma se propôs a eliminar. Deste modo, o homem voltou ao estado de encantamento com um mundo de produções fantásticas, mas alienado de sua compreensão.

Preocupado com os (des)caminhos que a ciência percorre em seu propósito de "iluminar" o progresso e o desenvolvimento da sociedade, este estudo intenta reestabelecer e atualizar a crítica, em especial aquela marcuseana, como elemento necessário para pôr em xeque o credo depositado na ciência, ainda que a desconfiança e a suspeita se mantenham como condição para tal. Mediante o referencial teórico frankfurtiano, refletiremos acerca do tipo de racionalidade operada a favor das descobertas tecnocientíficas, questionando as implicações destas para a dinâmica social contemporânea e seus desdobramentos éticos. Por estarmos interessados em discutir os posicionamentos da Teoria Crítica sobre os conceitos de razão, técnica e progresso, de modo a balizar nosso debate sobre a produção científica que se converte em mercadoria tecnológica para uso humano, este trabalho tem por base por uma concepção de ciência politicamente implicada com os ideais humanitários de igualdade e orientada para o diagnóstico do presente, com vistas a possíveis transformações da sociedade.

Assim, com o alinhamento teórico-metodológico à Teoria Crítica, especialmente aquele vinculado à Herbert Marcuse, tornamos clara a nossa posição em favor da emancipação humana, "[...] ao mesmo tempo possível e bloqueada pela organização social vigente” (LIMA, 2010, p.32). A discussão que se segue também tem por meta denunciar a dominação que se dá pela via da tecnociência, cuja crítica desvela o paradoxo de uma racionalidade científica voltada para o mercado e alheia aos ideais emancipatórios.

\section{A problemática do progresso e a Critica à Ciência em Herbert Marcuse}

O pensamento de Marcuse (2001) evidencia uma atitude crítica partilhada pelos pensadores da Escola de Frankfurt que tem em seu arcabouço teórico fundamentais influências do pensamento marxista, além da visão freudiana de homem - trata-se, pois, da concepção de um sujeito do inconsciente caracterizado pelo conflito entre as forças pulsionais e os sacrifícios demandados pela vida em sociedade. Para Marcuse, na civilização moderna ocidental, o progresso é entendido prioritariamente como quantitativo e instrumental, na medida em que

\begin{tabular}{|c|c|c|c|c|}
\hline Rovista Dialectus & Ano 8 & n. 14 & Janeiro - Julho 2019 & p. $121-146$ \\
\hline
\end{tabular}


tem como objetivo prioritário uma crescente riqueza social. Os esforços empreendidos para aumentar os meios de satisfação das necessidades humanas estão fortemente relacionados com a criação dessas necessidades como fruto do desenvolvimento da civilização. Deste modo, Marcuse identifica que o progresso dominante em nossa sociedade, nomeado por ele "progresso técnico", diferencia-se do progresso por ele designado como "progresso humanitário". Neste último, teríamos contribuições voltadas para o aperfeiçoamento qualitativo humano, focando igualmente em "uma existência mais livre e mais feliz" (p. 100).

Sobre as relações entre progresso técnico e humanitário, Marcuse (2001) afirma que o segundo tem como precondição o primeiro, pois, a "[...] ascensão da humanidade a partir da escravidão e da miséria a uma liberdade cada vez maior pressupõe o progresso técnico" ( p.100), porém, não seria de modo automático que um levaria ao outro. É denunciado, assim, que a riqueza social obtida pela via do progresso técnico não é repartida ou experimentada de modo igual na sociedade e que os "[...] crescentes conhecimentos e capacidades dos seres humanos" (p. 100) são empregados a serviço da dominação do homem pelo homem, trazendo prejuízos para a emancipação dos sujeitos, além de relegar o progresso humanitário ao plano da utopia. Para o pensador frankfurtiano, a sociedade industrial moderna conserva como mais alto valor a produtividade, “[...] não somente no sentido de aumentar a produção de bens materiais e intelectuais, mas também no sentido de uma dominação universal da natureza” ( p.102).

Assim, defendemos uma ciência identificada com a conquista do progresso humanitário, consoante ao que foi descrito por Marcuse (2001):

[...] o progresso consiste na história, na realização da liberdade humana, na moralidade: cada vez mais homens se tornariam mais livres, e a própria consciência da liberdade seria um estímulo como que para um aumento no âmbito da liberdade. Assim, o resultado do progresso seria que os homens se tornariam cada vez mais humanos, verificando-se uma regressão na escravatura, na arbitrariedade, na opressão, na dor. A este conceito qualitativo de progresso podemos chamar a ideia do progresso humanitário (p. 100).

Segundo Marcuse (2001), se o progresso técnico é pré-requisito para o progresso humanitário, uma vez que este tornou-se aliado unicamente ao fator econômico como juiz de sua produtividade, resta uma ausência de direcionamento para o saneamento das questões humanitárias que permitiriam maior igualdade e liberdade aos homens - seja em relação ao mercado (na condição de consumidores), seja em relação ao trabalho (na condição de produtores explorados). Dessa maneira, o incremento técnico parece aprofundar a dominação e

\begin{tabular}{|c|c|c|c|c|}
\cline { 2 - 4 } Q Q Onialectus & Ano 8 & n. 14 & Janeiro - Julho 2019 & p. $121-146$ \\
\hline
\end{tabular}


a exploração cada vez mais sutil das consciências, suprimindo seu potencial para a formação de homens mais livres. Nas palavras de Marcuse (2001):

o progresso técnico parece ser a pré-condição de todo progresso humanitário que consiste na realização da liberdade humana: um número cada vez maior de seres humanos torna-se livre. $\mathrm{O}$ resultado do progresso aqui consiste na humanização progressiva dos homens (p. 113).

De modo prevalente, entendemos que o progresso humanitário é negligenciado, permanecendo ofuscado, quando não paralisado pelo progresso técnico - este que deveria, justamente, criar as condições e premissas básicas, em face da riqueza social acumulada, para impulsionar o progresso humanitário. De tal sorte que o progresso humanitário parece estar à deriva e sua relação com o progresso técnico resta enfraquecida e conflituosa, uma vez que este é pensado desvinculado de suas necessidades sociais. O progresso humanitário, assim, permanece no âmbito da promessa, tendo sido deslocado para o campo da utopia, tal como nos observou Marcuse: “[...] o elemento qualitativo do progresso se vê cada vez mais levado a seguir o caminho da utopia” (p.133), uma vez que jamais triunfa sobre o progresso técnico. $\mathrm{O}$ triunfo da técnica no modo de conceber o progresso tem implicações políticas que devem ser consideradas nesta análise. Marcuse (1973) manifesta-se de modo a evidenciar as consequências das criações humanas para a realidade que estabelecemos e prossegue com seu posicionamento:

O a priori tecnológico é um a priori político na medida em que a transformação da natureza compreende a do homem, e na medida em que as "criações feitas pelos homens" provêm de um conjunto social e a ele retornam. (...) quando a técnica se torna a forma universal da produção material, ela circunscreve uma cultura inteira; ela projeta uma totalidade histórica - um "mundo" (p. 150).

A grande contribuição dos frankfurtianos é exatamente denunciar a capacidade da ciência de se desumanizar e promover o aprofundamento da barbárie, valendo-se de sua reputação de promotora do desenvolvimento tecnológico para, internamente, contrabandear para seus produtos: a exploração objetiva (dos trabalhadores) e subjetiva (dos consumidores). Desenha-se, assim, os fortes contornos de uma sociedade desigual e com desenvolvimento humanitariamente precário. Parte desse processo resulta em uma confusão sobre essa ideia de progresso, uma vez que, em virtude do privilégio concedido ao desenvolvimento científico pautado no progresso técnico, este é confundido com o progresso em si. Isto favorece o esquecimento do progresso humanitário e promove sua exclusão da agenda assumida pela ciência moderna. Para Horkheimer (2007), “a racionalização progressista tende [...] a obliterar

\begin{tabular}{|l|l|l|l|l|}
\hline Gevista Dialectus & Ano 8 & n. 14 & Janeiro - Julho 2019 & p. $121-146$ \\
\hline
\end{tabular}


a própria substância da razão em nome da qual se apoia a causa do Progresso" (p. 8). Este problema também é comentado por Sfez (1996) ao destacar que: “[...] o progresso tecnológico é identificado com o próprio progresso e não é um simples instrumento do progresso. Só a tecnologia pode ter um efeito real sobre a ordem social, considerada como um vasto empreendimento" (p. 114).

O progresso apresenta-se em dois polos diametralmente opostos. De um lado, colecionam-se "milagres", "salvações" e produtos capazes de auxiliar o homem no desenvolvimento de suas potencialidades e na realização de atividades antes pensadas como impossíveis. E por outro lado, espalha destruição, morte e "catástrofes", como afirma Benjamin (1986). Dissertar sobre o progresso é estar no centro de um processo "[...] tanto fascinante e sedutor quanto repulsivo e aterrador" (SOARES, 1997, p. 3). Assim, de modo similar, um paradoxo é trazido à evidência por Marcuse (2001), na medida em que este se questiona sobre o próprio sentido do conceito de progresso e o modo como são orientadas as necessidades humanas, trazendo ao cerne da questão estas necessidades que se configuram como norteadoras de progresso.

[...] quando o conceito de necessidade engloba tanto alimentação, roupa, moradia quanto bombas, máquinas caçaníqueis e a destruição de produtos invendáveis, então podemos afirmar como certo que o conceito é tão desonesto quanto inútil para determinar o que seria uma produtividade legítima, e temos o direito de deixar em aberto a pergunta: produtividade pra quê? (MARCUSE, 2001, p. 102).

Ao tentar responder a esse questionamento, somos levados à suposição de que tal produtividade é o combustível de nossa sociedade e que, sem ela, a sociedade movida pelas relações e trocas comerciais vai experimentar níveis de circulação de capital inferiores e decrescentes. A paralisação da crítica e o desprezo diante da necessidade de refletir sobre a filosofia que reside por traz da produção de conhecimento científico levam a crer, segundo Etienne Klein (2007), que, “[...] a ciência se transformou numa empresa exclusivamente produtivista" (p. 269). Em Horkheimer (2007) encontramos fundamento para a problemática da desumanização do homem resultante de sua maquinização respaldada pelo progresso técnico-científico. Segundo ele,

parece que enquanto o conhecimento técnico expande o horizonte da atividade e do pensamento humanos, a autonomia do homem enquanto indivíduo, a sua capacidade de opor resistência ao crescente mecanismo de manipulação de massas, o seu poder de imaginação e o seu juízo independente sofreram aparentemente uma redução. $O$ avanço dos recursos técnicos de informação se acompanha de um processo de desumanização (p. 7).

\begin{tabular}{|c|c|c|c|c|}
\cline { 2 - 4 } & Ano 8 & n. 14 & Janeiro - Julho 2019 & p. $121-146$ \\
\hline
\end{tabular}


Temos, portanto, uma significa articulação entre a maquinização operada pelo progresso científico e neutralização que este aplica sobre si mesmo. Marcuse (2001) constatou “[...] na formulação filosófica do conceito de progresso uma tendência manifesta a neutralizar o próprio progresso" (p. 101). Tal concepção de progresso, livre de valorações e apoiado em uma frágil e falsa neutralidade, é a contribuição de Comte e sua ciência positivista. Como consequência disto, nos é explicado que "[...] o progresso passou a estar relacionado com a solução ou a contemporização de problemas imediatos e pontuais, e não mais com o núcleo qualitativo e significativo da vida, como ocorria no Iluminismo" (LEOPOLDO E SILVA, 2008, p. 169). Sobre a pretensa neutralidade atribuída também à ciência moderna como instância representante do progresso, Marcuse (2009) denuncia que: “[...] a ciência está ameaçada pelos seus próprios progressos, ameaçada por seu avanço como instrumento de um poder livre de valores, em vez de um instrumento de conhecimento e verdade" (p. 164).

É interessante pensar que, enquanto a ciência positivista propaga valores de neutralidade em relação às produções em acordo com sua orientação filosófica, oculta em si uma predileção pelo progresso técnico e uma escolha conveniente e excludente do progresso humanitário. Quando falamos dos avanços da tecnociência, então, essa polarização, que não deveria ser contrária ou excludente, parece se ampliar e, assim, retirar completamente a possibilidade de progresso humanitário de seus propósitos, ao passo que legitima o progresso técnico como decisão racional e imparcial. Ao comentar sobre isso, Matos (2006, apresenta a ideia de Adorno sobre os aspectos ideológicos da técnica e da racionalidade que a opera. Segundo ela, na obra Discretas Esperanças,

nova figura da ideologia, "o véu tecnológico" e o capital se associam em um mundo no qual tudo se apresenta como decisão técnica. Concentracionário, é administrado, "é prisão a céu aberto". Para Adorno, o cientismo, defesa acrítica e inquestionável dos primados e práticas da ciência - é ciência que acarreta adesão ao fatum na própria ciência, na política, no mercado. A ideologia da racionalidade tecnológica gera cega obediência às exigências do desenvolvimento capitalista, pois a técnica se pretende neutra e imparcial a ideologia transforma-se em potência invisível (p. 79).

Sobre as verdades e os produtos que a ciência produz e legitima, um ponto a ser refletido é relativo precisamente nossa incapacidade de perceber a lógica que operacionaliza e fundamenta tais produções. Massivamente, permanecemos apáticos e aparentemente deficitários em nossa capacidade de questionar a visão de mundo e de homem que nos vendem. Assim, a realidade parece ser planejadamente manufaturada para nosso consumo fascinado pelos objetos produzidos cientificamente. Parecemos incapazes de desconfiar dos valores

\begin{tabular}{|c|c|c|c|c|}
\cline { 2 - 4 } Q Oonista & Ano 8 & n. 14 & Janeiro - Julho 2019 & p. $121-146$ \\
\hline
\end{tabular}


criados e legitimados que nos são ofertados nos produtos das "vitrines" por sua associação à ciência. Menos ainda, parecemos capazes de suspeitar das práticas e interesses que determinam a produção científica nos dias de hoje. De tão naturalizadas e celebradas, essas práticas não ensejam nenhum desconforto ou estranhamento. Sobre isso, Marcuse (1999) alerta, em sua denúncia sobre a gradual adesão da ciência à racionalidade tecnológica, e consequentemente mercadológica: "a ciência moderna desenvolveu-se em conflito com os poderes que se opunham à liberdade de pensamento; hoje a própria ciência encontra-se em aliança com os poderes que ameaçam a autonomia humana e frustram a tentativa de realizar uma existência livre e racional" (p. 163).

A vanguarda dos produtores de tecnologia e seus produtos mais avançados servem a uma parcela reduzida da população. É aquela elite tecnológica e financeira, entretanto, que comanda a produção de mercadorias para a satisfação de necessidades criadas pelo próprio sistema de produção que mobiliza os desejos mediante a "autoridade" dos meios de comunicação. Isto acontece não unicamente com os produtos puramente tecnológicos, mas também com fármacos, veículos, educação, moradia etc. Compreendemos, no entanto, que a tecnologia de "ponta" é experimentada de modo bastante restritivo, tornando, por exemplo, o acesso a tratamentos de saúde com certas drogas impossível para um homem de rende mediana.

Entendemos que o mercado abriga várias demandas manufaturadas e as ciências suprem as necessidades de criação de novidades na busca por sucesso de vendas a converter-se em lucro. A tecnologia instrumentaliza as empresas nesse processo de criação de produtos ofertados como distintivos socioculturais. Sobre esse processo de criação de novidades para a movimentação do mercado, concordamos com Novaes (2009), ao nos dizer que a estratégia "[...] da aceleração total econômica e tecnológica se fundava no princípio da seleção, e que o sujeito humano ia desaparecer no vetor da tecnologia. Podemos, pois, concluir que as transformações da técnica têm mais impacto na nossa maneira de viver do que a política" (p. 32). Aqui, percebemos que a técnica, com seus valores de eficiência e aceleração, formatam o nosso modo de viver e por isso é afirmado que está, não à frente ou acima da política, mas inserida na política, na produção, na educação e em todos os campos do viver humano como política de desenvolvimento e modus operandi; constituindo-se em uma nova forma de dominação.

Os frankfurtianos empreenderam a crítica à racionalidade tecnológica, que apesar de ter promovido extraordinários recursos para domínio da natureza pelo humano, por outro, criou meios de aniquilar a raça humana. Os desdobramentos científicos como fruto desta

\begin{tabular}{|c|c|c|c|c|}
\cline { 2 - 5 } Q Povista & Ano 8 & n. 14 & Janeiro - Julho 2019 & p. $121-146$ \\
\hline
\end{tabular}


racionalidade específica são analisados e ponderados para questionar se estes estariam, de fato, cumprindo sua promessa de "iluminar" a humanidade e emancipar os homens de todas as modalidades de dominação. O desprezo acerca da reflexão sobre os fins últimos do progresso, seus aspectos éticos, humanitários e qualitativos, resulta em desigualdades sociais estendidas a todo o planeta. Observamos em diversas partes do globo a luta por sobrevivência contra a fome e contra doenças com alto índice de mortalidade, consideradas inofensivas e controladas em regiões favorecidas economicamente. Afinal, a direção do processo histórico de nossas civilizações condiciona que o locus de nascimento de uma pessoa no nosso planeta determinará o nível de exploração e dominação a que ela estará submetida, ou destinará ao indivíduo os meios para que este dê continuidade à dominação de outrem. A dialética do esclarecimento indica exatamente isto: “[...] o progresso ameaça anular o que se supõe ser o seu próprio objetivo: a ideia de homem" (HORKHEIMER, 2007, p. 7). Adorno (1992), aprofunda a discussão ao afirmar que:

nessa questão está envolvida toda a dialética do esclarecimento, ela é tão racional quanto irracional: racional, na medida em que torna consciente a idolatria, irracional ao voltar-se contra seu próprio objetivo, o qual só está presente onde não precisa se justificar diante de Instância alguma ou mesmo diante de intenção alguma ( p.105).

O posicionamento teórico dos pensadores da Escola de Frankfurt é o de negar qualquer neutralidade científica. Adorno e Horkheimer (1991), na "Dialética do Esclarecimento", empreendem uma análise aprofundada dos elementos da racionalidade do mundo moderno para denunciá-los como uma nova forma de dominação, caracterizada pela previsibilidade e uniformização das consciências. A crítica filosófica da cultura realizada, neste contexto, demonstra o fracasso do programa do esclarecimento, cuja promessa de salvar o mundo dos grilhões da superstição, da ignorância e do medo através da soberania do homem e de seu domínio sobre a natureza, resultaram frustrados. O Esclarecimento, segundo esses autores, apresentou-se predominantemente em sua face coercitiva: O homem, em sua tentativa de domínio sobre a natureza, findou por desenvolver um domínio totalitário sobre os próprios homens. A razão, ao pretender conciliar-se com a realidade, terminou por degradar-se a si mesma, transformando-se em uma razão encurtada, formalizada e fatídica: uma razão instrumental, mera justificação mistificadora do imediato, estranha à realidade concreta dos homens e ao seu mundo de vida. O único critério de verdade deste tipo de racionalidade passou a ser o seu valor operativo, ou seja, sua capacidade de eficácia na dominação da natureza. Isto porque a razão, ao alienar-se da reflexão sobre seus fins e valores, despoja-se de qualquer juízo

\begin{tabular}{|c|c|c|c|c|}
\cline { 2 - 4 } & Ano 8 & n. 14 & Janeiro - Julho 2019 & p. $121-146$ \\
\hline
\end{tabular}


ético, político ou valorativo sobre o homem, perdendo seus poderes de crítica e transformandose num instrumento de legitimação da ordem dominante e de adequação do homem aos limites do fato estabelecido. Entretanto, vale ressaltar que não era à razão em si que estes autores criticaram, mas um tipo de racionalidade que passou a predominar principalmente após a consagração da epistemologia do Positivismo, no século XIX, enquanto a "legítima" representante da Ciência Moderna.

Horkheimer (1983) estabelece importantes diferenças entre "teoria tradicional" e "teoria crítica" para compreensão da práxis científica defendida pelos pensadores da referida Escola. Esta última é caracterizada como dotada de uma atitude que mobiliza a produção teórica a intervir na prática, negando a realidade positivada como a única possível, a fim de que as possibilidades de transformação emerjam, opondo-se, desta maneira, à ideologia de neutralidade própria da teoria tradicional. A teoria crítica concebe a relação entre sujeito da ciência e objeto da ciência como orgânica e politicamente implicada. Considera o sujeito do conhecimento em sua condição de "[...] analista e crítico da situação, buscando colaborar na intervenção e no redirecionamento do processo histórico em favor da emancipação dos homens em uma ordem social justa e igualitária” (FREITAG, 1988, p. 42). Sobre a inaptidão da teoria tradicional para proporcionar mudanças significativas na sociedade, Horkheimer (1983) evidencia que a ciência, assim como outros campos de trabalho, reproduz a dinâmica da divisão de trabalho mantenedora da sociedade capitalista. Segundo ele,

\begin{abstract}
a representação tradicional de teoria é abstraída do funcionamento da sociedade, tal como este ocorre a um nível dado da divisão do trabalho. Ela corresponde à atividade científica tal como é executada ao lado de todas as demais atividades sociais, sem que a conexão entre as atividades individuais se tome imediatamente transparente. Nesta representação surge, portanto, não a função real da ciência nem o que a teoria significa para a existência humana, mas apenas o que significa na esfera isolada em que é feita sob as condições históricas. Na verdade, a vida da sociedade é um resultado da totalidade do trabalho nos diferentes ramos de profissão, e mesmo que a divisão do trabalho funcione mal sob o modo de produção capitalista, os seus ramos, e dentre eles a ciência, não podem ser vistos como autônomos e independentes (p. 123).
\end{abstract}

Deste modo, obtemos uma compreensão maior acerca da heteronomia operada sobre o trabalho científico, resultando em proposições consoantes à manutenção das contradições que perduram a revelia do potencial libertador da razão. Paralisam-se, assim, os ímpetos capazes de conduzir a sociedade a mudanças promotoras de maior justiça social por intermédio de produções científicas implicadas com a melhoria da sociedade em seu caráter opressor. Sobre a singularidade da teoria crítica, Horkheimer explica que:

\begin{tabular}{|l|l|l|l|l|}
\cline { 2 - 5 } & Ano 8 & n. 14 & Janeiro - Julho 2019 & p. $121-146$ \\
\hline
\end{tabular}


a sua oposição ao conceito tradicional de teoria não surge nem da diversidade dos objetos nem da diversidade dos sujeitos. Para os representantes desse comportamento, os fatos, tais como surgem na sociedade, são frutos do trabalho. E, como tais, não são exteriores no sentido em que o são para o pesquisador ou profissional, que se imagina a si mesmo como um pequeno cientista. Para eles é importante um nova organização do trabalho. Os fatos concretos que estão dados na percepção devem despojar-se do caráter de mera facticidade na medida em que forem compreendidos como produtos do homem que, como tais, deveriam estar sob o controle humano e que, em todo o caso, passarão futuramente a este controle (p. 132).

O posicionamento ora descrito é de enorme relevância para que se desmistifique a pretensa neutralidade do discurso científico por via da qual a dominação se insere e se mantém velada. Oriunda das ciências naturais, esta neutralidade é posta em dúvida e o positivismo é criticado como uma modalidade inadequada de explicar os fenômenos humanos e sociais, em virtude da impossibilidade de estabelecer uma separação entre sujeito e objeto do conhecimento, ou mesmo, desejar tal separação. A ciência positivista é compreendida como uma interpretação da realidade desprovida de seus aspectos histórico-culturais, condicionantes dos fenômenos estudados, legitimando, assim, a ordem social presentificada. Por isso, para reverter esse quadro de produção científica, segundo Horkheimer (1983), é preciso “[...] passar para uma concepção que elimine a parcialidade que resulta necessariamente do fato de retirar os processos parciais da totalidade da práxis social” (p. 124). Em sua obra As Razões do Iluminismo, Rouanet (1987) assinala que, contemporaneamente, a razão se exprime, tal como agente da dominação, em oposição ao seu projeto inicial de emancipação do homem. Segundo o referido autor:

as vanguardas do alto modernismo perderam sua capacidade de escandalizar e se transformaram em establishment; os grandes mitos oitocentistas do progresso em flecha e a emancipação da humanidade pela ciência ou pela revolução são hoje considerados anacrônicos; a razão, instrumento com que o Iluminismo queria combater as trevas da superstição e do obscurantismo, é denunciada como principal agente da dominação (p. 230).

Exprimimos, portanto, a noção de que, em alguns momentos, o espírito crítico direcionado aos dogmas não se manteve operando com igual rigor sobre os fins da própria ciência. Esse "descuido" foi e é capaz de conduzir cegamente a humanidade a própria tragédia, na medida em que a não reflexão crítica sobre a própria finalidade da ciência pode torná-la um novo mito (ADORNO E HORKHEIMER, 1991), promover a submissão dos homens e instrumentalizar a criação de produtos capazes de causar a destruição da vida no planeta. Os embates bélicos ocorridos nos últimos 100 anos mostraram que, em matéria de capacidade de destruição, o homem é um grande perigo para a humanidade. Esta foi a preocupação que animou

\begin{tabular}{|c|c|c|c|c|}
\cline { 2 - 4 } Q Q Onialectus & Ano 8 & n. 14 & Janeiro - Julho 2019 & p. $121-146$ \\
\hline
\end{tabular}


Adorno e Horkheimer ao problematizar os ideais do esclarecimento, os quais, segundo eles, resultaram frustrados. A dialética do esclarecimento representa esse desenvolvimento humano contraditório, no qual progresso e regressão, construção e destruição, justificam-se ambos, pelo advento da razão. Em suas palavras:

no sentido mais amplo do progresso do pensamento, o esclarecimento tem perseguido sempre o objetivo de livrar os homens do medo e de investi-los na posição de senhores. Mas a terra totalmente esclarecida resplandece sob o signo de uma calamidade triunfal. O programa do esclarecimento era o desencantamento do mundo[...].Contudo, a credulidade, a aversão à dúvida, a temeridade no responder, o vangloriar-se com o saber, a timidez no contradizer, o agir por interesse, a preguiça nas investigações pessoais, o fetichismo verbal,[...] impediram um casamento feliz do entendimento humano com a natureza das coisas (p. 19).

A relação entre calculabilidade, utilidade e esclarecimento é problematizada por Adorno e Horkheimer (1991) para evidenciar que a ciência moderna se muniu de uma racionalidade peculiar para operar no mundo e pela via da redução ao calculável, útil e praticável fez uso da lógica formal para produzir o conhecimento esclarecido. Percebemos aqui, nas palavras dos teórico-críticos da Escola de Frankfurt, uma negligência ou falha do esclarecimento com aquilo que se exprime como diverso, irredutível e complexo. Nesta crítica feita à mistificação do esclarecimento expressam seu desagravo:

[...] o esclarecimento só reconhece como ser e acontecer o que se deixa captar pela unidade. Seu ideal é o sistema do qual se pode deduzir toda e cada coisa. (...) A multiplicidade das figuras se reduz à posição e à ordem, a história ao fato, as coisas à matéria. A lógica formal era a grande escola da unificação. Ela oferecia aos esclarecedores o esquema da calculabilidade do mundo. (...) O número tornou-se o cânon do esclarecimento (p. 22).

Neste ponto, vemos que este caráter singular e inapreensível dos fenômenos, não ajustável às fórmulas e aos cálculos, denuncia uma racionalidade incompleta e parcial, apoiando-se num pretenso discurso de imparcialidade para descortinar as "verdades". Observamos que essa abordagem positivista dominante na ciência moderna privou-se de considerar um compêndio de conhecimentos e valores sobre o humano e sua história, com sérias implicações para a compreensão do fenômeno humano em sua totalidade, tornando-se um modelo pragmático e reducionista. Como nos confirmam Adorno e Horkehimer (1991), a busca dos cientistas pelo conhecimento, em face do critério da calculabilidade, está distanciada do sentido e do conceito, imprescindíveis para a compreensão do homem e sua existência:

poder e conhecimento são sinônimos. [...] O que importa não é aquela satisfação que, para os homens, se chama 'verdade', mas a 'operation', o procedimento eficaz.[...] No trajeto para a ciência moderna, os homens renunciaram ao sentido e substituíram o conceito pela fórmula, a

\begin{tabular}{|l|l|l|l|l|}
\hline Gevista Qialectus & Ano 8 & n. 14 & Janeiro - Julho 2019 & p. $121-146$ \\
\hline
\end{tabular}


causa pela regra e probabilidade. [...] A filosofia buscou sempre, desde Bacon, uma definição moderna de substância e qualidade, de ação e paixão, do ser e da existência, mas a ciência já podia passar sem semelhantes categorias. [...] O que não se submete ao critério da calculabilidade e da utilidade torna-se suspeito para o esclarecimento (p. 18-19).

Desta maneira, posicionamo-nos contrários ao progresso meramente técnico, calculista e utilitarista, em prol de repensá-lo em seu viés qualitativo, na defesa da emancipação humana bloqueada por esta racionalidade dominante. Como afirma Olgária Matos (2006), acreditamos que, para tal objetivo libertador, “[...] requer revolucionar a ciência e a técnica, tornadas forças produtivas e fundamento da legitimação política do capitalismo tardio, colonizadoras de todo o mundo da vida segundo uma racionalidade instrumental" (p. 17). Com este posicionamento, a autora corrobora a ideia de Marcuse sobre o componente político da técnica, legitimando, assim, o sistema de exploração do humano no capitalismo vigente.

Matos (2006) prossegue com sua definição e reúne dominação, violência e sacrifício da natureza como características por intermédio das quais a racionalidade dominante se concretiza, criando inclusive uma “[...] justificativa intelectual para o massacre dos nativos do Novo mundo [...] pelo desconhecimento do método, do raciocínio por hipóteses, e verificações da Razão Instrumental" (p. 92). Apresentar um modo de pensamento distinto, orientado por outros valores, é ameaçador ao primado da técnica e, inúmeras vezes, a racionalidade instrumental, justifica sua barbárie. Se essa racionalidade já foi capaz de fundamentar aniquilações no passado em nome do progresso e da liberdade, no presente, esse fundamento se direciona igualmente contra aquilo que foge ao seu domínio. Vale ressaltar aqui a aderência historicamente estabelecida entre a ciência e a guerra que favorece o desenvolvimento bélico elevando a capacidade de destruição do ser humano. Além das máquinas nucleares, atômicas, “inteligentemente mortíferas" como produções científicas, a transformação do homem em sua relação com as máquinas e os desenvolvimentos tecnocientíficos também ocorre impulsionada pelo militarismo. Como evidência dessa relação, Crary (2014) denuncia os estudos militares feitos para um controle sobre a redução ou eliminação do tempo de sono e, consequente, aumento do tempo de vigília a ser dedicado à sobrevivência, inicialmente na guerra, e com possível aplicação cotidiana posterior, para os sujeitos civis na "guerra do capitalismo". Afinal, "no paradigma neoliberal globalista, dormir é, acima de tudo, para os fracos" (p. 23). Ele relata que:

devem se entender os estudos sobre privação de sono no contexto de uma busca por soldados cujas capacidades físicas se aproximaram cada vez mais da eficácia de aparatos e redes não humanos. O complexo científico militar vem se dedicando a pesquisa de formas de cognição

\begin{tabular}{|l|l|l|l|l|}
\cline { 2 - 4 } Q Povista & Ano 8 & n. 14 & Janeiro - Julho 2019 & p. $121-146$ \\
\hline
\end{tabular}


ampliada que prometem aprimorar a interação entre homem e máquina simultaneamente, as forças armadas têm financiado diversas outras áreas de investigação do cérebro, bancando inclusive o desenvolvimento de uma droga contra o medo (p. 13).

Ainda sobre a relação entre ciência e guerra no contexto histórico global, Crary (2014) estabelece a segunda guerra mundial como grande marco para o estabelecimento do mundo global, tecnológico e comunicacional em que vivemos. Em suas palavras:

\begin{abstract}
a Segunda Guerra Mundial, em seu caráter destrutivo e impacto global, constituiu um evento inédito de homogeneização, no qual foram destruídos por completo territórios, identidades e tecidos sociais ultrapassados. Ela criou, na medida do possível, uma tábula rasa que seria a plataforma da atual fase da globalização do capitalismo. A segunda guerra mundial foi o cadinho no qual se forjaram novos paradigmas de comunicação, informação e controle, e no qual se consolidaram as conexões entre pesquisa científica, corporações nacionais e poder militar (p. 77).
\end{abstract}

Observamos hoje, como consequência do continuum histórico agora descrito, que as guerras são motivadas pela dominação capaz de incrementar a produção e os fluxos de capital. Podemos citar aqui a noção de que algumas das guerras mais recentes, como no Iraque e Afeganistão, guardavam em sua fundamentação a ideia de que era preciso libertar os povos de regimes totalitários, mesmo que pela paradoxal via da bárbarie ${ }^{2}$. Assim, percebemos a contradição em submeter outros povos à liberdade por uma via repressiva, pensada segundo o modelo ocidental liberal, portanto, uma liberdade heterônoma que se impõe de modo violento. Sobre esta força da libertação de povos para a fruição das 'maravilhas ocidentais globalizadas' vividas no consumo de bens, serviços e entretenimentos, o próprio Marcuse (1973), já nos advertira para os riscos da pseudoliberdade:

sob o jugo de um todo repressivo, a liberdade pode ser transformada em poderoso instrumento de dominação. $\mathrm{O}$ alcance da escolha aberta ao indivíduo não é o fator decisivo para a determinação do grau de liberdade humana, mas o que pode ser escolhido e o que é escolhido peIo indivíduo (p. 28).

Observamos nesse processo de relativização da liberdade, que ela é complacente com a dominação e justificada economicamente. Contemporaneamente, como efeito destas elaborações e condições históricas que favoreceram a legitimação do saber científico, a racionalidade instrumental está materializada na maneira de o homem compreender o mundo,

2 Para um aprofundamento, conferir o texto “Adorno e a Crítica da Barbárie: um Olhar Psicanalítico" de Sérgio Paulo Rouanet na obra "Escola de Frankfurt: inquietudes da razão e da emoção" (2010) organizado por Jorge Coelho Soares.

\begin{tabular}{|c|c|c|c|c|}
\cline { 2 - 4 } Q Q Dialectus & Ano 8 & n. 14 & Janeiro - Julho 2019 & p. $121-146$ \\
\hline
\end{tabular}


explicá-lo e sobre ele agir, descartando aquilo que não se submete ao cálculo, como nos disse Adorno e Horkheimer (1991). Deste modo, essa racionalidade se expande e domina o estilo de pensar científico e suas formas de intervir no mundo, acelerando e enfatizando o progresso tecnológico aliado à eficiência econômica. Entendemos que essa relação entre economia e produção científica é problemática ao traficar para o campo da ciência os anseios das intempéries do competitivo mercado, orientado por produtividade e lucro. Marcuse (2009) diz que, "na medida em que a economia se torna um sistema tecnológico, a ciência se transforma num fator decisivo nos processos econômicos da sociedade. [...] A ciência literalmente abastece a economia" (p. 163). Desta maneira, o pensador alemão afirma que "o poder tecnológico tende à concentração do poder econômico" (MARCUSE, 1999, p. 76).

Nesse sentido, a crítica, a reflexão, a justiça social, a solidariedade e a ética não são valores "convidados" aos juízos elaborados sob a égide da racionalidade técnica, estando o desenvolvimento da ciência cada vez mais determinado pelos valores competitivos do mercado e da aceleração tecnológica. Consoante esta ideia, Soares (2002) explica que,

presos à lógica de uma racionalidade técnica, capaz de produzir o melhor e o pior dos mundos, acreditando ser a razão prática a única forma de lidar com a realidade e consigo mesmo, o sujeito, construtor deslumbrado da técnica, se expôs, aceleradamente, como objeto de desconstrução de si mesmo. [...] Cientifização, racionalização - aumento de eficiência de valores exclusivamente funcionais da 'idade tecnológica' - foram otimizados ao extremo com toda sutileza possível, apontando na direção do triunfo da 'razão instrumental' (p. 40).

Assim, a racionalidade dominante na sociedade é internalizada pelo homem e este opera no mundo seguindo seus valores fundamentais que instrumentalizam e modelam nosso modo de pensar o mundo e atuar sobre ele. Habermas (1968), em capítulo de homenagem aos 70 anos de Marcuse, descreve o posicionamento do homenageado sobre o caráter falho da racionalidade no que se refere a sua atuação unicamente no sentido de realizar a "correta eleição entre estratégias, a adequada utilização de tecnologias e a pertinente instauração de sistemas (em situações dadas para fins estabelecidos)" (p. 46). Ou seja, apesar da submissão de diversas esferas sociais ao controle, que poderia pressupor um caráter racional, esta submissão redunda em parcial racionalidade, estabelecendo um modelo que opera em nome da racionalidade, mas de "uma forma determinada de dominação política oculta" (p. 46) e, portanto, favorecendo a “institucionalização da dominação" (p.46) e impossibilitando a "[...] reflexão e reconstrução racional" (p. 46). Habermas, ao explicar sobre a centralidade da ação dirigida à fins na produção da racionalidade instrumental, afirma que:

\begin{tabular}{|c|c|c|c|c|}
\cline { 2 - 4 } & Ano 8 & n. 14 & Janeiro - Julho 2019 & p. $121-146$ \\
\hline
\end{tabular}


essa racionalidade estende-se, além disso, apenas às situações de emprego possível da técnica e exige, por isso, um tipo de ação que implica dominação quer sobre a natureza ou sobre a sociedade. A ação racional dirigida à fins é, segundo a sua própria estrutura, exercício de controles. Por conseguinte, a 'racionalização' das relações vitais segundo critérios desta racionalidade equivale a institucionalização de uma dominação que, enquanto política, se torna irreconhecível: a razão técnica de um sistema social de ação racional dirigida a fins não abandona o seu conteúdo político (p. 46).

Deste modo, a crítica feita ao conteúdo político da racionalidade decorre da dominação que se evidencia sobre seus objetos, reproduzida claramente na relação da ciência moderna entre pesquisador e pesquisado, sujeito e objeto de estudo, concebidos como separados em face aos métodos modernos da racionalização. Essa relação torna-se problemática quando as ciências sociais tomam esse modelo de distanciamento, próprio das ciências naturais, porém, agora, tendo o homem em ambos os polos: como pesquisador e feito pesquisado. Nossa crítica refere-se à percepção de que desde a relação da ciência com vistas à manipulação de seus objetos de estudo, esse domínio e tal controle racional se constituem como modelos de dominação dos homens para com os homens. Isto se ilustra na ação racional do empresário capitalista, que tem como objeto o trabalhador industrial ou empregado moderno, difundindo a exploração do homem e da natureza, pelo homem. Neste sentido, Marcuse afirma que: "[...] o conceito de razão técnica é talvez também em si mesmo ideologia. Não é a sua aplicação, mas já a própria técnica e dominação metódica, científica, calculada e calculante (sobre a natureza e sobre o homem)" (MARCUSE, 1998, p.46). Adorno e Horkheimer partilham dessa ideia ao afirmarem que "o que os homens querem aprender da natureza é como empregá-la para dominar completamente a ela e aos homens. Nada mais importa" (p. 18).

\section{A "Neutralidade" da Técnica e da Tecnologia segundo Marcuse - notas sobre os processos de dominação}

Objetivando privilegiar a discussão que envolve as noções de técnica e de tecnologia para os pensadores da Escola de Frankfurt, em especial Marcuse (1999), delineamos uma breve evolução destes conceitos no decorrer de sua obra. Inicialmente, em seus escritos, era possível perceber que Marcuse concebia a técnica como neutra, entendida como despretensiosamente associada à adaptação do homem à natureza, enquanto a tecnologia era concebida como a transformação da técnica para finalidades de dominação. No primeiro pensamento, a técnica guarda em si uma possibilidade de uso identificada com a libertação do homem. Posteriormente, “[...] revisando o marxismo à luz de novas forças históricas que entraram em cena” (PISANI,

\begin{tabular}{|c|c|c|c|c|}
\cline { 2 - 4 } Q Q Onialectus & Ano 8 & n. 14 & Janeiro - Julho 2019 & p. $121-146$ \\
\hline
\end{tabular}


2009, p. 137), no seu texto A Ideologia da Sociedade Industrial, em função do contato com as ideias de Heidegger, em A Questão da Técnica, e Husserl, em A Crise das Ciências Européias e a Fenomenologia Transcendental, seu posicionamento é atualizado e a neutralidade da ciência e da técnica é rejeitada. Marcuse (1973) expressa que

em face das particularidades totalitárias desta sociedade, a noção tradicional de tecnologia não pode mais ser sustentada. A tecnologia não pode, como tal, ser isolada do uso que lhe é dado; a sociedade tecnológica é um sistema de dominação que já opera no conceito e na elaboração das técnicas (p. 19).

Desta maneira, Marcuse se reposiciona em relação ao papel da técnica e sua lógica de dominação, considerando que a racionalidade instrumental permanece a ela associada. Velada por todo o aparato tecnológico que encarna o espírito progressista da ciência, da produtividade e da eficiência econômica, reside esta racionalidade que se justifica essencialmente por sua prevalência econômica. Assim, mediante o conceito de tecnicidade, Marcuse expressa ideias sobre a impossibilidade de manter sua noção anterior de técnica como "indiferente ou neutra". Para ele, a tecnicidade, um aspecto inerente à técnica, traduz-se em dominação. Como valor dominante, a capacitação técnica também se beneficiou de sua "propaganda", como tendência a ser seguida e dominada pelos trabalhadores, ainda que a dominação do homem também ocorresse, aparentemente, sem levantar suspeitas. Esta relação entre técnica e dominação é exposta por Benjamin (2012) ao explicar que

nada corrompeu mais as classes trabalhadoras alemãs do que a ideia de que elas estavam integradas na corrente dominante. O desenvolvimento técnico foi visto por elas como o declive da corrente que julgavam acompanhar. Daqui até a ilusão de que o trabalho na fábrica, visto como fazendo parte desse progresso técnico, representava uma conquista política, foi apenas um passo. A velha moral protestante do trabalho, agora em forma secularizada, comemorava com os trabalhadores alemães a sua ressurreição (p. 15).

Nas palavras de Benjamin (2012), é possível perceber que a técnica, enquanto conquista política, foi ofertada e aparentemente aceita de modo tanto entusiasmado e quanto voluntarioso - e isto por suscitar nas pessoas o sentimento de pertencimento e a impressão de participação no mundo moderno das fábricas. Deste modo aquilo que é dominante (no sentido de prevalecer e controlar) e a capacidade de dominação gradualmente universalizam-se por meio desta disposição e disponibilidade das populações em adotarem a tecnicidade como virtude a ser desenvolvida. A explicação de Marcuse (1992) sobre as condições criadas para a soberania da

\begin{tabular}{|c|c|c|c|c|}
\cline { 2 - 4 } & Ano 8 & n. 14 & Janeiro - Julho 2019 & p. $121-146$ \\
\hline
\end{tabular}


técnica como meio e fim último capazes de universalizar a dominação é vista no seguinte trecho:

\begin{abstract}
se levarmos em conta esse caráter existencial da tecnicidade, podemos falar de uma causa final tecnológica e de seu recalcamento pelo desenvolvimento social da técnica. [...] A técnica, desenvolvendo-se atualmente como instrumentalidade "pura", fez abstração da causa final: ela deixou de ser o objetivo do desenvolvimento tecnológico. Como consequência, a instrumentalidade pura, sem finalidade, tornou-se um meio universal de dominação (p. 135-6).
\end{abstract}

A negação deste componente da dominação é necessária para o redirecionamento que tencionamos provocar rumo a uma reconsideração de valores e conhecimentos avaliados hoje, predominantemente, como obsoletos. A banalização e a naturalização desta característica tornam esse aspecto da humanidade uma espécie de "gene dominante da racionalidade" ou um “a-historicismo inato" (ADORNO, 1992, p. 9), tamanha é sua prevalência. Esta marca impressa historicamente conserva em si um esquecimento de nosso passado e/ou um bloqueio de nossas possibilidades de mudança.

Em busca de se adaptar e se perpetuar como espécie, a dominação inicialmente direcionada sobre a natureza em prol do homem transformou-se também em dominação do homem sobre o homem na sociedade capitalista, como expusemos. Esta é encontrada nas relações entre grupos, ou seja, verificamos a dominação de povos sobre povos, nas colonizações pré e pós-industriais e nos monopólios comerciais vigentes nos dias de hoje. Esta dominação é empreendida em favor de interesses particulares e identificada como historicamente constituída, naturalizada pela posição histórica da natureza como objeto da dominação técnica repressiva, em oposição a sua vertente libertadora. Deste modo, Marcuse (1973) estabelece como meta utópica a pacificação, oriunda de uma utilização da dominação em seu caráter libertador. Ele explica que “[...] o propósito de pacificação determina o logos da técnica, ele altera a relação entre tecnologia e seu objeto primordial, a Natureza. Mas há dois tipos de domínio: o repressivo e o libertador. Este compreende a redução da miséria, da violência e da crueldade” (p. 218).

Desta maneira, Marcuse se posiciona de modo a indicar um uso não repressivo da Razão. Por meio de uma definição de uma nova relação da ciência com a natureza, esta, seria objeto de libertação: "Se a Natureza é em si um objeto racional e legítimo da Ciência, então ela é o objeto legítimo não apenas da Razão como poder, mas também da Razão como liberdade; não apenas de dominação, mas também de libertação" (p. 218). Deste ponto, Marcuse (1973) vislumbra uma reconfiguração dos valores empreendidos pela dominação, transformando-a em

\begin{tabular}{|c|c|c|c|c|}
\cline { 2 - 4 } Q Q Onialectus & Ano 8 & n. 14 & Janeiro - Julho 2019 & p. $121-146$ \\
\hline
\end{tabular}


uma dominação da racionalidade com fins de equilibrar o progresso, operando como fator de liberação. Sobre esta mudança necessária da racionalidade tecnológica, Marcuse afirma:

[...] a racionalidade tecnológica, despida de suas particularidades exploradoras, é o único padrão e guia do planejamento e do desenvolvimento dos recursos disponíveis para todos. A autodeterminação na produção e distribuição de bens e serviços vitais seria perdulária. A tarefa é técnica e, como uma tarefa verdadeiramente técnica, possibilita a redução da labuta física e mental. Nesse reino, o controle centralizado é racional se estabelece as precondições da autodeterminação significativa. Esta pode então tornar-se eficaz em sua própria esfera - nas decisões que envolvem a produção e a distribuição do excedente econômico, e na existência individual (p. 231).

A utopia descrita por Marcuse opõe-se e vem a substituir um sistema que em sua essência perpetuou a dominação do homem pelo homem. O estabelecimento desta ordem unidimesnionalizada ocorre porque "os instrumentos de produtividade e progresso, organizados em sistema totalitário, determinam não apenas as utilizações reais, mas também as possíveis" (p. 233). Desta maneira, a irracionalidade ganha contornos de racionalidade sofisticada. A dominação avançada é descrita como purificada ao se tornar eficaz, ou seja: "em sua fase mais avançada, a dominação funciona como administração. E nas áreas superdesenvolvidas de consumo em massa, a vida administrada se torna a boa vida de todos" (p. 234). No propósito de refletir sobre as alternativas futuras, Marcuse aponta para o caminho da pacificação da luta pela existência e, portanto, para o fim da dominação do homem sobre o homem:

uma vez que o desenvolvimento com a utilização de todos os recursos disponíveis para a satisfação universal das necessidades vitais é o requisito da pacificação, esta é incompatível com o prevalecimento de interesses particulares que se interpõem ao alcance dessa meta. A modificação qualitativa está condicionada ao planejamento para o todo contra esses interesses, e uma sociedade livre e racional só pode surgir nessas bases (p. 230).

A pacificação descrita, porém, implicaria na eliminação da dominação do homem pelo homem progressivamente racionalizada ao longo da história e revertida em favor de interesses particulares. Estes fins de lucratividade e produtividade obtidos por via da exploração indiscriminada da natureza dariam lugar a outras finalidades pensadas para o coletivo. Precisarse-ia estabelecer nova modalidade de relação, abandonando a condição de objeto da dominação repressiva. Adorno (1995) partilha de preocupações semelhantes sobre o futuro que a humanidade. Ele alerta que,

hoje, tais reflexões culminam na consideração sobre se a humanidade será capaz de evitar a catástrofe. São de vital importância para a humanidade as formas de sua própria constituição global, enquanto não se constitui e intervém um sujeito global consciente de si mesmo.

\begin{tabular}{|c|c|c|c|c|}
\cline { 2 - 4 } & Ano 8 & n. 14 & Janeiro - Julho 2019 & p. $121-146$ \\
\hline
\end{tabular}


Exclusivamente sobre isso recai a possibilidade de progresso, a possibilidade de afastar a catástrofe extrema, total. Nisso deveriam cristalizar-se todos os problemas relativos ao progresso (p. 39).

Marcuse expressa que "a sociedade seria racional e livre desde que fosse organizada, mantida e reproduzida por um sujeito histórico essencialmente novo" (p. 230). Ao operar racionalmente esta mudança, a história se recondicionaria correlatamente à posição da natureza, e, desta maneira, seria possibilitada seu redirecionamento de modo libertador. Com isto, Marcuse assinala que,

[...] o que está em jogo é a redefinição dos valores em termos técnicos, como elementos do progresso tecnológico. Os novos fins, como fins técnicos, operariam então no projeto e na construção da maquinaria e não apenas em sua utilização. Mais ainda, os novos fins podem reafirmar-se até mesmo na construção de hipóteses científicas - na teoria científica pura. Da quantificação das qualidades secundárias, a ciência passaria à quantificação dos valores (p. 217).

Portanto, para um equilíbrio entre as racionalidades distintas, capazes de promover um progresso orientado para o desenvolvimento das potencialidades humanas de modo livre, nos é afirmado por Marcuse (1973) “[...] uma redução tanto qualitativa como quantitativa do poder, a fim de criar o espaço para o desenvolvimento da produtividade sob incentivos autodeterminados" (p. 218). Tal mudança ocasionaria, utopicamente, uma libertação da energia física e mental hoje "[...] canalizada para o manuseio de mercadorias e serviços” (p. 224). Desta forma, "a libertação de energia de desempenhos exigidos para manter a prosperidade destrutiva significa baixar o alto padrão de servidão a fim de permitir aos indivíduos desenvolverem aquela racionalidade que pode tornar possível uma existência pacificada (p. 224).

Inicialmente, Marcuse considerou que o progresso técnico e o processo cada vez mais acelerado de automação, implicaria numa inevitável redução de mão-de-obra e tornaria obsoleta a necessidade de trabalhar em tempo integral. Como a energia utilizada no trabalho/labuta é retirada principalmente de Eros, com a diminuição deste trabalho, tal energia retornaria à esfera do erótico e ocuparia o conjunto do organismo, mobilizando, desta forma, a totalidade das atividades humanas. Como consequência, o trabalho continuaria indispensável, no entanto, não mais subordinado ao "princípio do desempenho" e à "mais repressão". O que seria eliminado é a "organização da existência humano como instrumento de trabalho" (p.85), o trabalho em si. Este seria erotizado, transformando-se em 'jogo' e possibilitando a criação de relações de trabalho novas e duráveis.

\begin{tabular}{|c|c|c|c|c|}
\cline { 2 - 4 } & Ano 8 & n. 14 & Janeiro - Julho 2019 & p. $121-146$ \\
\hline
\end{tabular}


A definição do nível de vida em termos de automóveis, televisões, aviões, e tratores é a do próprio 'princípio de desempenho'... o nível de vida poderia ser medido por outros critérios: a gratificação universal das necessidades humanas básicas e a liberdade contra a culpa e o medo tanto internalizado como externo, tanto instintivo como 'racional'. (p. p.86).

Entretanto, se em seu livro "Eros e Civilização", escrito em 1955, Marcuse tenta estabelecer as condições para o advento de uma utopia fundada na liberação de Eros, em sua obra posterior "A Ideologia da Sociedade Industrial - o homem unidimensional" escrito em 1964, ele põe o acento nas dificuldades crescentes à constituição do 'sujeito revolucionário', visto a aderência quase completa do indivíduo à ordem unidimensional, que com seu aparato tecnológico e uma sofisticada rede de comunicações de massa manipula e falsifica as consciências individuais, eliminando assim as condições subjetivas capazes de gerar uma atitude de oposição crítica à ordem estabelecida. Tal posicionamento pode ser constatado em seu prefácio à edição de 1966 de "Eros e Civilização":

Eros e Civilização: com esse título eu pretendia expressar uma ideia otimista, eufemística, aliás concreta: a convicção de que os resultados alcançados pelas sociedades industrias avançadas pudessem permitir ao homem inverter o rumo da evolução histórica, quebrar o vínculo fatal entre produtividade e destruição, liberdade e repressão - pudessem, em outras palavras, por o homem em condições de aprender a gaia ciência, ou seja, a arte de utilizar a riqueza social para modelar o mundo do homem segundo os seus instintos de vida, através de uma luta concentrada contra os agentes da morte. Essa visão otimista baseava-se na hipótese de que não mais predominassem os motivos que, no passado, haviam tornado aceitável o domínio do homem sobre o homem; que a escassez e a necessidade do trabalho como esforço fossem mantidos agora de modo apenas 'artificial', com a finalidade apenas de preservas o sistema de dominação. Naquele momento eu havia negligenciado ou minimizado o fato de que esses motivos, agora em processo de extinção, tinham sido enormemente reforçados (e não substituídos) por formas ainda mais eficientes de controle social. Precisamente, as forças que puseram a sociedade em condições de resolver a luta pela existência serviram para reprimir nos indivíduos a necessidade da libertação". (MARCUSE, 1975, p.90).

Portanto, Marcuse claramente decepciona-se com os rumos do progresso, em face das novas formas de dominação prevalentes nas sociedades modernas, as quais decretaram a “irracionalidade objetiva do sistema", já apontada na Dialética do Esclarecimento e referida aqui, anteriormente, a qual se funda, justamente, nessa discrepância entre "progresso tecnológico" e "progresso humanitário", em que ocorre uma distribuição irracional dos bens objetivos e subjetivos que a civilização já conquistou. Isto porque, apesar de todo o progresso tecnológico já alcançado, o modo como a riqueza social, o saber acumulado e as aptidões humanas foram orientadas não redundaram em "progresso humanitário" com vistas à extinção

\begin{tabular}{|l|c|c|c|c|}
\hline Govista Dialectus & Ano 8 & n. 14 & Janeiro - Julho 2019 & p. $121-146$ \\
\hline
\end{tabular}


progressiva da miséria e do trabalho alienado; mas ao invés, resultaram em uma subordinação cada vez maior do homem ao aparato produtivo e de consumo, concebido como um fim em si mesmo. (Marcuse, 1973; Adorno e Horkheimer, 1991).

Contemporaneamente, observamos a perpetuação da dominação, ainda de forma mais sofisticada e racionalizada em acordo com os avanços do capital financeiro. Sobre este processo de evolução da dominação, Marcuse expressa que:

\begin{abstract}
na realidade social, a dominação do homem pelo homem ainda é, a despeito de toda transformação, o contínuo histórico que une Razão pré-tecnológica e Razão tecnológica. Contudo, a sociedade que projeta e empreende a transformação tecnológica da natureza altera a base da dominação pela substituição gradativa da dependência pessoal (o escravo, do senhor; o servo, do senhor da verdade; o senhor, do doador do feudo etc.) pela dependência da 'ordem objetiva das coisas'(das leis econômicas, do mercado etc). Sem dúvida, a 'ordem objetiva das coisas' é, ela própria, o resultado da dominação, mas é, não obstante, verdade que a dominação agora gera mais elevada racionalidade - a de uma sociedade que mantém sua estrutura hierárquica enquanto explora com eficiência cada vez maior os recursos naturais e mentais e distribui os benefícios dessa exploração em escala cada vez maior (p.142).
\end{abstract}

A economia e o mercado, cada vez mais, mostram relações estreitas com a produção científica, ao ponto de as próprias pesquisas serem determinadas, em seus objetivos e desenvolvimento, não pelos cientistas, mas pelos seus financiadores, norteados pelo princípio de rendimento no mercado. De tal sorte que, os empreendimentos científicos pouco dependem de sua eficiência como incremento ou melhoria das carências humanas a serem aplacadas pelos seus resultados. Sua eficiência está ligada ao seu sucesso enquanto empreendimento mercadológico.

A não adesão à ordem mercantil vigente, identificada com o progresso tecnológico instrumentalizante resulta no " [...] banimento gradual dos sonhadores, dos pensadores utópicos, dos poetas, dos homens sensíveis, dos divergentes e outsiders de todo tipo para os domínios da loucura e da exclusão social" (SOARES, 1997, p. 3). As demandas por adaptação a essa ordem instrumental tornam a dominação cada vez mais naturalizada:

vivemos em um mundo que não gosta da revolta nem da crítica, que acredita plenamente na ordem natural das coisas e que pede a cada um e a todos para se adaptarem, por um simples "cálculo" individual. O mundo contemporâneo não gosta da "universalidade", tendo no dinheiro sua única exceção. Somos todos definidos como consumidores, não como cidadãos, muito menos como pessoas (SOARES, 2002, p. 38).

\title{
Considerações Finais
}

\begin{tabular}{|c|c|c|c|c|}
\cline { 2 - 4 } Q Dovista & Ano 8 & n. 14 & Janeiro - Julho 2019 & p. $121-146$ \\
\hline
\end{tabular}


Em face ao exposto, nosso entendimento cumplicia com o diagnóstico de que os (des)caminhos da ciência e da técnica, em sua relação com o homem e a natureza, tendem a um progressivo processo de dominação e desejo de controle - isto consiste, pois, em uma característica dominante do "homem da ciência", ou das "teorias tradicionais", na definição de Horkheimer (1983). É paradoxal, do ponto de vista humanitário e ético, que em face das capacidades técnicas já exponencialmente desenvolvidas, os homens não tenham conseguido tornar os problemas efetivamente coletivos, vinculados à questão central da desigualdade social. Entretanto, o paradoxo é apenas aparente. Sob a perspectiva em que nos situamos para a elaboração do diagnóstico referido por esse estudo, torna-se nítida a opção pelas razões mercantis no transcurso do desenvolvimento científico. Isso nos faz refletir sobre a abertura operada para atacar esses problemas, considerando que a exploração do homem pelo homem é o sustentáculo do sistema capitalista. Assim, como uma dada racionalidade justificou a superioridade ariana para Hitler, visões de mundo racionais pautadas na eficiência e no mero cálculo seguem justificando contemporaneamente a manutenção da barbárie, da miséria, da guerra, da exploração e da injustiça.

Boaventura Sousa Santos (2002) apresenta explicação de grande valia para nosso estudo sobre as frentes de desenvolvimento nas quais a sociedade progride. Seu pensamento guarda similaridade com as proposições marcuseanas sobre o progresso técnico e o progresso humanitário. Observamos nas ideias abaixo um singular modo de compreender os acontecimentos que parecem ter levado a paralisar a crítica e a intensificar a dominação e o controle. Ao falar do desenvolvimento do conhecimento, o autor exprime que

todo o acto de conhecimento é uma trajectória de um ponto A que designamos por ignorância para um ponto B que designamos por conhecimento. No projeto da modernidade podemos distinguir duas formas de conhecimento: o conhecimento-regulação cujo ponto de ignorância se designa por caos e cujo ponto de saber se designa por ordem e o conhecimento-emancipação cujo ponto de ignorância se designa por colonialismo e cujo ponto de saber se designa por solidariedade. Apesar de estas duas formas de conhecimento estarem ambas inscritas na matriz da modernidade eurocêntrica a verdade é que o conhecimento-regulação veio a dominar totalmente o conhecimento-emancipação (p. 29).

Quanto menos caminhamos rumo à emancipação, mais estaremos imersos sob o desejo (e práticas!) de regulação. Assim, entendemos que o exercício da lógica da dominação se beneficia da ignorância e da exploração colonialista que se opera, inclusive, dentro dessa dinâmica nas formas de conhecimento em que o poder se manifesta sob a égide da submissão, obediência, alienação e impotência.

\begin{tabular}{|c|c|c|c|c|}
\cline { 2 - 4 } & Ano 8 & n. 14 & Janeiro - Julho 2019 & p. $121-146$ \\
\hline
\end{tabular}


Em decorrência da suspeição levantada sobre as relações mercadológicas com a ciência, fica clara a defesa feita em prol de recobrarmos uma consciência ética condizente com os ideais de emancipação humana e a derrocada dos mitos. As dificuldades são inerentes à sistemática implementada para operar a mínima mudança nas atuais condições de reencantamento. É preciso resistir inventando uma criatividade e racionalidade outras. Ao tratar dessa sistemática à prova de reversão, Marcuse (1999) assim se pronuncia:

a questão é que atualmente o aparato ao qual o indivíduo deve ajustar-se e adaptar-se é tão racional que o protesto e a libertação individual parecem, além de inúteis, absolutamente irracionais. O sistema de vida criados pela indústria moderna é da mais alta eficácia, conveniência e eficiência (p. 82).

A tecnologia nos dispositivos móveis de comunicação representa, nos dias de hoje, fonte de "contato" com tudo o que já foi criado pela humanidade e também com aquilo que ainda não o foi, mas já se projeta ficcionalmente. A natureza e os homens são encontrados também em suas maneiras substitutivas e virtuais, que apaixonam o homem pelo espírito tecnológico sacralizado - e que é, hoje, anunciado como o "salvador da humanidade".

Em todos os âmbitos da atividade humana, o indivíduo contemporâneo é demandado a mostrar aptidões imediatas de modo a prescindir do pensamento reflexivo: o imperativo é o de reagir, mais que refletir; comprovar, mais que analisar; apresentar dados, mais que questionar; mostrar resultados, mais que produzir sentidos. O saber-fazer é substituído pela performance; a formação, pelo treinamento; a reflexão ética sobre os saberes e direcionamentos dos produtos da ciência, pela racionalidade instrumental mercantil.

O diagnóstico de Marcuse de que a técnica sempre encarna um Projekt, no qual são projetados os interesses dominantes da sociedade e suas intenções com relação aos homens e às coisas, segue atual:

A racionalidade tecnológica ter-se-á tornado racionalidade política [...]. O aparato técnico de
produção e distribuição não funciona como a soma total de meros instrumentos que possam ser
isolados de seus efeitos sociais e políticos, mas como um sistema que determina, a priori, tanto
o produto do aparato como as operações de sua manutenção e ampliação. [...]. A tecnologia serve
para instituir formas novas, mais eficazes e mais agradáveis de controle social e coesão social.
(MARCUSE, 1982, pp. 14-19).

Deste modo, em face da permanência, da exacerbação, do transbordamento e do exaurimento das desigualdades sociais e econômicas na contemporaneidade, concluímos que as facilidades auferidas pelos atuais recursos da tecnociência não propiciaram subsídios para um caminho rumo à emancipação. Pelo contrário: atrela-o cada vez mais à lógica do capital,

\begin{tabular}{|l|c|c|c|c|}
\cline { 2 - 4 } & Ano 8 & n. 14 & Janeiro - Julho 2019 & p. $121-146$ \\
\hline
\end{tabular}


capturando-o nos produtos da ciência aplicada e nos objetos de consumo. E isso com o agravante de vampirizar e sorver, cada vez mais, um tempo supostamente liberado do trabalho e da produção - trata-se, pois, de um mundo 24-7, de alerta onipresente, suscitado e excitado mediante próteses tecnológicas a demandar uma insaciável competitividade, sem quaisquer reflexões sobre seus fins. Hoje, como ontem, o "progresso tecnológico" segue não resultando em "progresso humanitário".

\section{Referências:}

ADORNO, Theodor. Mínima Moralia. São Paulo: Ática. 1992.

. Educação após Auschwitz. In: ADORNO, T.W. Educação e emancipaçãa. Rio de Janeiro: Paz \& Terra, 1995a. p. 119-138.

. Progresso. In: ADORNO, T.W. Palavras e sinais: modelos críticos 2. Petrópolis: Vozes, 1995b. p. 37-61.

\& HORKHEIMER. Dialética do esclarecimento: fragmentos filosóficos (1947). 2. Ed. Rio de Janeiro: Jorge Zahar Editor, 1991.

ALVES, Giovanni. Trabalho e Subjetividade: O Espírito Do Toyotismo na Era do Capitalismo Manipulatório. São Paulo: Boitempo, 2011.

BENJAMIN, Walter. Documentos de Cultura, documentos de barbárie. (Textos escolhidos). São Paulo: Cultrix, 1986.

SCHÖTTKER, D., BUCK-MORSS, S., HANSEN, M., Benjamin e a obra de arte: técnica, imagem, percepção. Rio de Janeiro: Contraponto, 2012.

CRARY, Jonathan. 24/7. Capitalismo tardio e os fins do sono. São Paulo: Cosac Naify, 2014.

FREITAG, Barbara. Teoria Crítica Ontem e Hoje, São Paulo: Brasiliense, 1988.

HABERMAS, Jurgen. Técnica e Ciência como Ideologia. Lisboa: Edições 70, 1968.

HORKHEIMER, Max. Teoria Tradicional e Teoria Crítica. In: HORKHEIMER, Max e ADORNO, Theodor. Textos Escolhidos,. São Paulo: Abril Cultural, 1983, p. 31-68.

Eclipse da Razão. São Paulo: Centauro, 2007.

KLEIN, Etienne. Questionando a Ciência in NOVAES, Adauto (org.). Ensaios sobre o Medo. São Paulo: Editora Senac São Paulo/ Edições Sesc SP, 2007, p. 253-266.

\begin{tabular}{|c|c|c|c|c|}
\cline { 2 - 4 } & Ano 8 & n. 14 & Janeiro - Julho 2019 & p. $121-146$ \\
\hline
\end{tabular}


LEOPOLDO E SILVA, Franklin. Descontrole do tempo histórico e banalização da experiência. Em NOVAES, Adauto (org.) Mutações. Rio de Janeiro: Ed. Agir, 2008a, p. 149-172.

LIMA, Aluisio Ferreira. Metamorfose, Anamorfose e Reconhecimento Perverso. São Paulo: FAPESP; EDUC, 2010.

MARCUSE, Herbert Ideologia da Sociedade Industrial. Rio de Janeiro: Zahar, 1973.

Eros e Civilização: uma interpretação filosófica do pensamento de Freud. Rio de Janeiro: Zahar, 1975.

Cultura e Sociedade. São Paulo: Paz e Terra, 1998.

Algumas Implicações Sociais da Tecnologia Moderna. In: Tecnologia, Guerra e Fascismo. Trad. Maria Cristina V. Borba. São Paulo: Ed. UNESP, 1999, p.73-104.

A Noção de Progresso à Luz da Psicanálise. In:. Cultura e Psicanálise. São Paulo: Paz e Terra, 2001, p.99-122.

64.

A Responsabilidade da Ciência in: scientiæ zudia, São Paulo, v. 7, n. 1, 2009, p. 159-

MATOS, Olgária. Discretas Esperanças. São Paulo: Editora Nova Alexandria, 2006.

NOVAES, Adauto. Entre dois Mundos in: NOVAES, A.. (org.) A Condição humana. Rio de Janeiro, Ed. Agir, 2009, p. 9- 37.

PISANI, Marília. Algumas considerações sobre ciência e política no pensamento de Herbert Marcuse. Scientiæ Zudia, São Paulo, v. 7, n. 1, 2009, p. 135-58.

ROUANET, Sérgio Paulo. As Razões do Iluminismo. São Paulo: Companhia das Letras, 1987. Nós, civilizações, sabemos que somos mortais in. NOVAES, Adauto. A condição humana. Rio de Janeiro, Ed. Agir, 2009. p. 185-198.

SANTOS, Boaventura de Sousa..Crítica da Razão Indolente. 4ed. São Paulo: Cortez, 2002.

SFEZ, Lucien. A Saúde Perfeita: crítica de uma nova utopia. São Paulo: Loyola, 1996.

SOARES, Jorge. Repensando a Noção de Progresso Globalizado. Conferência III Semana Gilberto Freyre, Recife, 1997.

. Em busca de uma "razão sensível" no reino da cultura de massa. In Logos: Comunicação e Universidade; Produção de Sentido na Contemporaneidade. Revista de Comunicação Social da UERJ, Ano 9. №. 17, 2002, p.33-44.

\begin{tabular}{|l|c|c|c|c|}
\cline { 2 - 4 } & Ano 8 & n. 14 & Janeiro - Julho 2019 & p. $121-146$ \\
\hline
\end{tabular}

